\title{
Clinical and histopathological analyses of VEGF receptors peptide vaccine in patients with primary glioblastoma - a case series
}

\author{
Ryota Tamura', Yukina Morimoto ${ }^{1}$, Kenzo Kosugi ${ }^{1}$, Mizuto Sato', Yumiko Oishi', Ryo Ueda', Ryogo Kikuchi',
} Hideaki Nagashima ${ }^{1}$, Tetsuro Hikichi ${ }^{4}$, Shinobu Noji ${ }^{3}$, Yutaka Kawakami ${ }^{3}$, Hikaru Sasaki ${ }^{1}$, Kazunari Yoshida ${ }^{1}$ and Masahiro Toda ${ }^{1 *}$ (D)

\begin{abstract}
Background: The expression of vascular endothelial growth factor (VEGF)-A/ VAGF receptors (VEGFRs) signaling plays a pivotal role in the tumor angiogenesis and the development of the immunosuppressive tumor microenvironment in glioblastomas. We have previously conducted exploratory clinical studies investigating VEGFRs peptide vaccination with and without multiple glioma oncoantigens in patients with recurrent high-grade gliomas. Recently, an exploratory clinical investigation of VEGFRs peptide vaccination was conducted in patients with progressive neurofibromatosis type 2. Those studies suggested that cytotoxic T lymphocytes (CTLs) induced by the vaccination can directly kill a wide variety of cells associated with tumor growth, including tumor vessels, tumor cells, and immunosuppressive cells expressing VEGFR1 and/or 2. In the present study, synergistic activity of the combination of VEGFRs peptide vaccination with chemotherapy was evaluated.
\end{abstract}

Methods: We performed the first clinical trial to assess VEGFR1 and 2 vaccination along with temozolomide (TMZ) -based chemoradiotherapy for the patients with primary glioblastomas. Furthermore, histopathological changes after the vaccination were evaluated using paired pre- and post- vaccination specimens.

Results: The disappearance of radiographically enhanced lesion was observed in 2 patients after the vaccination, including one in which the methylation of the O6-methylguanine-DNA methyltransferase (MGMT) promoter was not observed. The histopathological findings of pre- and post-vaccination specimens demonstrated that tumor vessels showed negative or slight VEGFRs expressions after the vaccination and most endothelial cells were covered with PDGFR- $\beta$-positive pericytes. Notably, CTLs induced by VEGFRs peptide vaccination attacked not only tumor vessels but also tumor cells and regulatory T cells expressing VEGFRs even in recurrent tumors.

Conclusions: VEGFR1 and 2 vaccination may have a preliminary synergistic effect when administered with TMZ. The limitation of the present study was the paucity of the number of the samples. Further studies involving more patients are warranted to confirm the findings of this study.

Trial registration: This study was registered as UMIN000013381 (University Hospital Medical Information NetworkClinical Trial Registry: UMIN-CTR) on 5 March, 2014 and with the Japan Registry of Clinical Trials (jRCT) as jRCTs0311 80170 on 1 March, 2019.

Keywords: VEGFR, Peptide vaccine, Glioblastoma, Bevacizumab

\footnotetext{
* Correspondence: todam@keio.jp

${ }^{1}$ Department of Neurosurgery, Keio University School of Medicine, 35

Shinanomachi, Shinjuku-ku, Tokyo 160-8582, Japan

Full list of author information is available at the end of the article
} 


\section{Background}

Angiogenic factors are important for the growth of malignant tumors, and vascular endothelial growth factor (VEGF)-A/ VEGF receptors (VEGFRs) signaling is the most potent [1]. Glioblastoma is a highly malignant tumor that exhibits extensive vascularity. The expression of VEGF-A/ VEGFRs is strongly upregulated in glioblastoma, and the expression degree correlates with the grade of malignancy and prognosis in malignant glioma $[2,3]$. It has been reported that both VEGFR1 and VEGFR2 are expressed on not only vascular endothelial cells, but also tumor cells [4]. VEGFR1 signaling is critical for tumor growth [5]. VEGFR2 plays an important role in the proliferation of tumor stem cells [6]. Furthermore, VEGF/VEGFR signaling plays a pivotal role in the development of the immunosuppressive tumor microenvironment in glioblastomas [7].

Therefore, VEGF-A and VEGFRs targeted antiangiogenic therapies have been previously used in glioblastomas. Bevacizumab, which targets circulating VEGF-A, and multikinase inhibitor, such as cediranib, sunitinib, and sorafenib, were associated with favorable event-free survival in patients with glioblastomas [8-12]. In addition, combinational therapy with anti-angiogenic therapy and chemotherapy has been an attractive treatment strategy in glioblastomas, because anti-angiogenic therapy induces a functional normalization of the tumor vasculature, increasing tumor cell exposure, and enhancing the activity of co-administered chemoradiotherapies [13]. The combinational therapy involving sorafenib plus daily temozolomide (TMZ), which is the primary chemotherapy used globally for glioblastoma treatment [14], was used for the recurrent glioblastomas, indicating that it is feasible, safe, and has some effect on patients [15].

Cancer immunotherapy has become the fourth preferred modality of cancer treatment after surgery and chemoradiotherapy. Peptide vaccination is an immunotherapy that aims to activate cytotoxic $\mathrm{T}$ lymphocytes (CTLs) in patients by inoculating antigen peptides. We have previously conducted exploratory clinical studies investigating VEGFRs peptide vaccination with and without multiple glioma oncoantigens in patients with recurrent high-grade gliomas [16, 17]. Recently, VEGFRs peptide vaccine was used in patients with progressive neurofibromatosis type 2 (NF2) [18]. In the study, the number of Foxp3-positive regulatory $\mathrm{T}$ cells (Tregs) decreased after the vaccination, suggesting that the CTLs induced by the vaccination can directly kill a wide variety of cells associated with tumor growth, including tumor vessels, tumor cells, and Tregs expressing VEGFR1 and/or VEGFR2. Furthermore, the combinational usage of chemotherapy and immunotherapy is also effective with synergistic activity [19], because chemotherapy suppressed immunosuppressive $\mathrm{T}$ cells and immunotherapy sustains the proliferation of potential effector immune cells $[20,21]$.

Based on these backgrounds, in this trial, VEGFR1 and 2 vaccine was used with TMZ-based chemoradiotherapy for the patients with primary glioblastomas [14]. VEGFRs peptide vaccination might have both the advantages of anti-angiogenic therapy and immunotherapy. In addition, we successfully evaluated the histopathological changes after the VEGFR1 and 2 vaccination using paired pre- and post-vaccination patient-derived specimens, proving the synergic effects when administered with chemotherapy.

\section{Methods}

\section{Trial overview}

The present study was an exploratory phase I and II clinical trial to assess the feasibility and effectiveness of VEGFR1 and 2 peptide vaccination in primary glioblastoma. All protocols were approved by the Keio University School of Medicine Ethics Committee (reference number: 20130461), and conducted in accordance with the Helsinki declaration on experimentation on human subjects. The trial was registered at UMIN (UMIN000023565) and jRCT (jRCTs031180170). The authors affirm that human research participants provided informed consent to participate in the study and for publication of their data.

\section{Patient eligibility}

Patients with high-grade glioma (WHO grade III or IV) after standard treatment (surgical removal + radiotherapy (RT) concomitant with TMZ [14]) were enrolled in this clinical study at the Department of Neurosurgery, Keio University School of Medicine. Patients also had to show positive for the genomic DNA typing test for HLA-A*2402 (HLA Laboratory, Kyoto, Japan). Details of the inclusion and exclusion criteria are provided in Table 1.

\section{Peptides}

Good manufacturing practice (GMP)-graded VEGFR1A24-1084 peptide (SYGVLLWEIF) and VEGFR2-A24169 peptide (RFVPDGNRI) were synthesized by BCN Peptides S.A. according to a standard solid-phase synthesis method and purified by reversed-phase highperformance liquid chromatography (HPLC). The purity (>95\%) and the identity of the peptides were determined by analytical HPLC and mass spectrometry, respectively. VEGFR1-A24-1084 and VEGFR2-A24-169 peptide (2 $\mathrm{mg}$ of each) were emulsified together with $1 \mathrm{ml}$ of incomplete Freund's adjuvant (Montanide ISA-51 VG, SEPPIC, Paris) and injected subcutaneously at infraaxillary and inguinal lymph nodes eight times every week and then six times monthly (a total of 14 times). 
Table 1 Inclusion and exclusion criteria

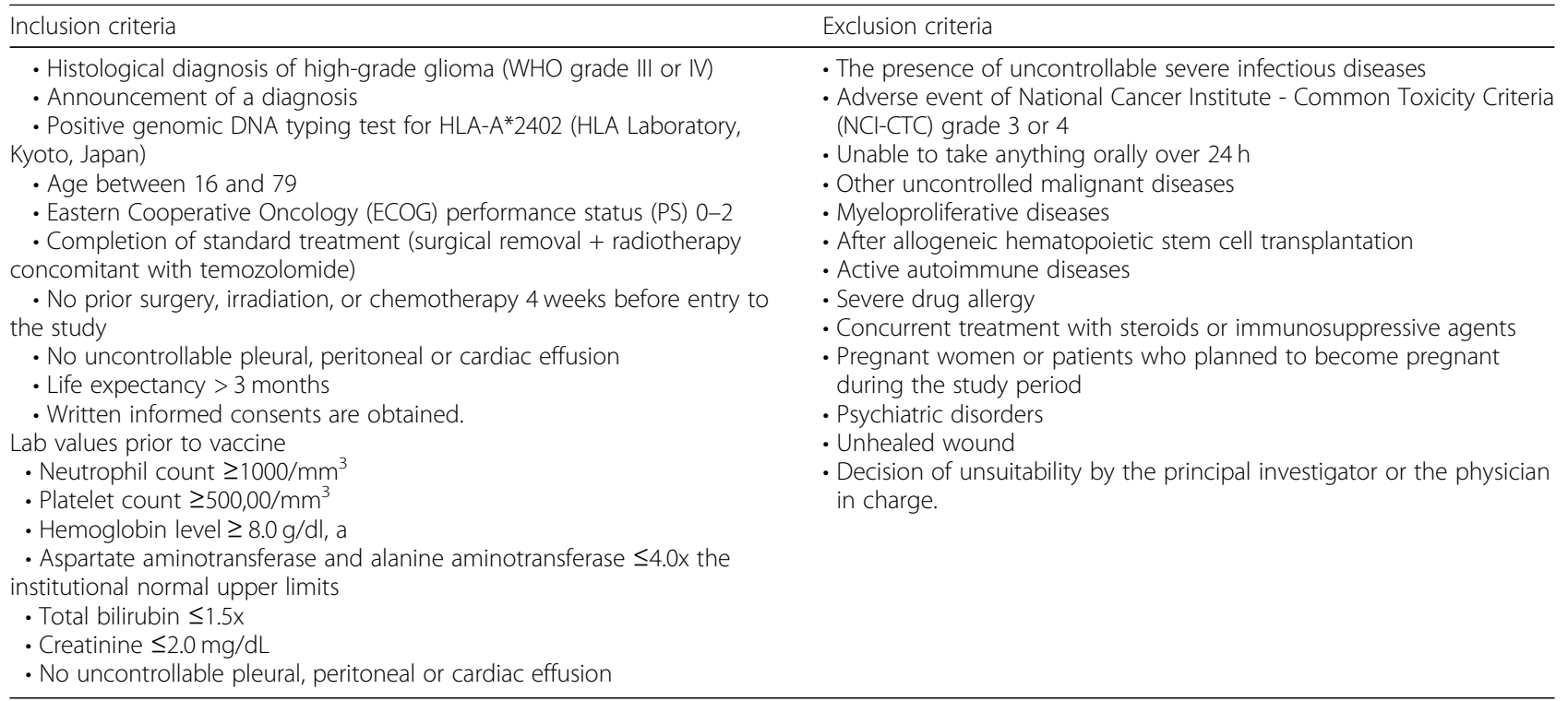

Vaccination was synchronized with adjuvant TMZ [14] (Fig. 1). The period of this study was 12 months starting after the 1 st vaccination.

\section{Outcomes and assessments}

The primary endpoints were safety and clinical efficacy of the vaccination [median overall survival (OS) time]. OS was defined as the interval from the date of commencement of treatment to the date of death. The secondary endpoints were radiographical and immunological responses. Toxicities were assessed with the Common Terminology Criteria for Adverse Events version 4.0 (CTCAE ver4.0) at each visit. To evaluate the clinical response, magnetic resonance imaging (MRI) were performed within 2 weeks before the first cycle, and then after 8, 12 and 14 cycles (3, 6, and 12 months). Radiographical response was evaluated by Response Assessment in Neuro-Oncology (RANO) and immunotherapy RANO (iRANO) using gadolinium (Gd) -enhanced T1 weighted images and fluid attenuated IR (FLAIR) on the basis of the appearance of the pretreatment MRI [22, 23]. Peptide-specific immunological responses were analyzed by EnzymeLinked ImmunoSpot (ELISPOT) assay (for details, see the Methods section in Additional file 3) [16, 24].

\section{Molecular-genetic analysis}

Chromosomal number aberrations (CNAs) were assessed by metaphase comparative genomic hybridization, as previously described [25]. Mutation of the isocitrate dehydrogenase (IDH)1 gene, and O6-methylguanine DNA methyltransferase (MGMT) promoter methylation, were also analyzed as previously described [16].

\section{Immunohistochemical analysis}

Histopathological analyses were performed on $4-\mu \mathrm{m} \mathrm{sec-}$ tions of formalin-fixed, paraffin-embedded tissues of paired pre- and post-vaccination obtained from Case 2. The expression of VEGF-A, VEGFR1, VEGFR2, CD34 (endothelial cell marker), PDGFR- $\beta$ (pericyte marker), programmed cell death-1 (PD-1) and programmed cell death ligand-1 (PD-L1) (immune-checkpoint molecules),

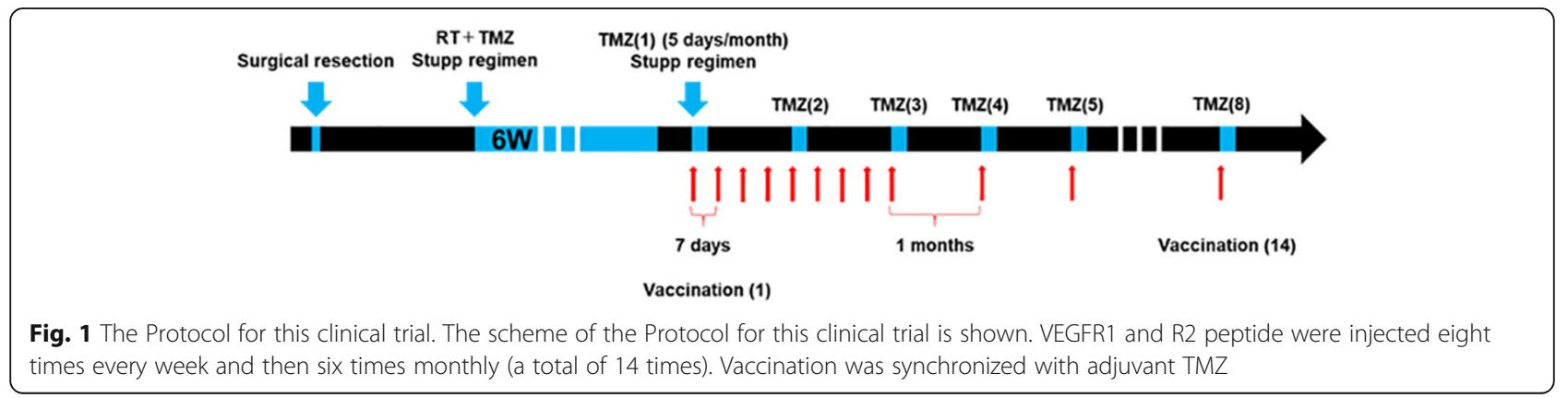


CD4 (helper T-cell marker), CD8 (CTL marker), Foxp3 (Treg marker), CD163 (tumor-associated macrophage [TAM] marker), nestin (neural stem/ progenitor cell marker), and cleaved caspase 3 (apoptosis marker) were analyzed [26, 27].

Immunofluorescence staining for VEGFR1, VEGFR2, and PDGFR- $\beta$ expressions or VEGFR1, VEGFR2, and cleaved caspase 3, CD34, VEGFR1 and cleaved caspase 3 , or Foxp3 and cleaved caspase 3 expressions was performed (for details, see the Methods section in Additional file 3).

\section{RNA extraction, cDNA synthesis, and quantitative real- time PCR}

For quantitative real-time PCR (qPCR) of VEGF-A, VEGFR1, VEGFR2 and Foxp3, RNA was isolated from $10-\mu \mathrm{m}$ sections of formalin-fixed, paraffin-embedded tissue using the "NucleoSpin total RNA FFPE XS" Kit (Macherey-Nagel) (for details, see the Methods section in Additional file 3) [28].

\section{Statistical analysis}

PFS was defined as the date elapsed between treatment initiation and tumor progression. OS and PFS were analyzed based on the Kaplan-Meier test. All statistical analyses were performed with IBM SPSS statistics. Differences were considered to be statistically significant when $p<0.05$.

\section{Results}

\section{Patient characteristics}

Four patients with primary glioblastoma were enrolled in this study (39-75 years old, two males and two females) between September 2014 and March 2018. All patients received 14 cycles of VEGFRs peptide vaccination (Table 2). All cases were IDH1-R132H wild-type and MGMT promoter methylation appeared in Case 2 and 4. 1,3-bis-Chloroethyl-1-Nitrosourea (BCNU) wafer was used in the surgical treatment of Case 2 and 3 . The data of CGH analysis are summarized in Table 2.

\section{Adverse events}

No major toxicity (grade 3 and 4) was found in this study. During this vaccination, Case 4 developed grade 1 local skin reaction at the injection sites with induration, redness, and swelling. No patients developed ulcers at the injection sites. No delayed wound healing or gastrointestinal bleeding were seen either. No other adverse events, such as arterial and venous thromboembolism, hypertension, and proteinuria, which were reported in the clinical study of bevacizumab, were detected.

\section{Clinical response}

Case 3 and 4 achieved complete response (CR). MGMT methylation was not detected in Case 3 (Fig. 2c, d). Although Gd-enhanced lesions were temporarily decreased in Case 1, and 2, Case 1 revealed progressive disease (PD) 10 months after the last vaccination and 9 months in Case 2 (Fig. 2a, b). In Case 2, the recurrent enhanced lesion was surgically removed again. The Kaplan-Meier curves for OS and PFS in four patients are shown in Fig. 3, respectively. At the time of analysis, Case 3 and 4 still showed CR (1425 and 962 days). Case 1 and 2 had already died (OS: Case 1, 967 days; Case 2, 1272 days).

\section{CD8+ T-cell response}

In Case 3 and 4, CTLs specific for both VEGFR1 and 2 were induced after vaccination. Immunological monitoring could not be performed for Case 1 and 2, as the samples were lost because of a deep freezer fault (Table 3).

\section{Histopathological analysis}

The histological changes using pre- and post-vaccination glioblastoma specimens could be analyzed in Case 2 . The analysis of endothelial cells stained by CD34 demonstrated that vessel diameter was smaller, and microvessel density (MVD) was lower after vaccination. Most tumor vessels exhibited strong VEGFRs expressions without PDGFR- $\beta$ positive pericytes before vaccination. In contrast, tumor vessels after vaccination showed

Table 2 Patients' Characteristics

\begin{tabular}{|c|c|c|c|c|c|c|c|c|c|c|}
\hline Case & Age & PS & $\begin{array}{l}\text { MIB-1 } \\
\text { index }\end{array}$ & $\begin{array}{l}\text { IDH1 } \\
\text { Mutation }\end{array}$ & $\begin{array}{l}\text { MGMT } \\
\text { Methylation }\end{array}$ & $\mathrm{CGH}$ & $\begin{array}{l}\text { Surgical } \\
\text { removal }\end{array}$ & Radiation & $\begin{array}{l}\text { TMZ } \\
\text { cycles }\end{array}$ & $\begin{array}{l}\text { Other } \\
\text { treatment }\end{array}$ \\
\hline 1 & 75 & 1 & 40.1 & wild & - & + 7p15.2-qter, $-10,-15 q,(-16 q c e n-13)$ & GTR & $\begin{array}{l}40 \mathrm{~Gy} / \\
15 \mathrm{fr}\end{array}$ & 22 & - \\
\hline 2 & 39 & 1 & 11.1 & wild & + & $\begin{array}{l}\text { +1pter-34.1, -9pter-21, - 10q21.1-ter, +13q12.2-31, +17p12- } \\
\text { q21.1,-18q23, -21q, +22qcen-13.1 }\end{array}$ & GTR & $\begin{array}{l}60 \mathrm{~Gy} / \\
30 \mathrm{fr}\end{array}$ & 31 & $\begin{array}{l}\mathrm{BCNU} \\
\text { wafer }\end{array}$ \\
\hline 3 & 52 & 0 & 30 & wild & - & -1 pter-36.1, $+7,-9$ pter-21, -10 & GTR & $\begin{array}{l}60 \mathrm{~Gy} / \\
30 \mathrm{fr}\end{array}$ & 14 & $\begin{array}{l}\text { BCNU } \\
\text { wafer }\end{array}$ \\
\hline 4 & 50 & 0 & 50 & wild & + & $+7,-10,+12 q 15,+13 q 14.3-33$ & GTR & $\begin{array}{l}60 \mathrm{~Gy} / \\
30 \mathrm{fr}\end{array}$ & 14 & - \\
\hline
\end{tabular}



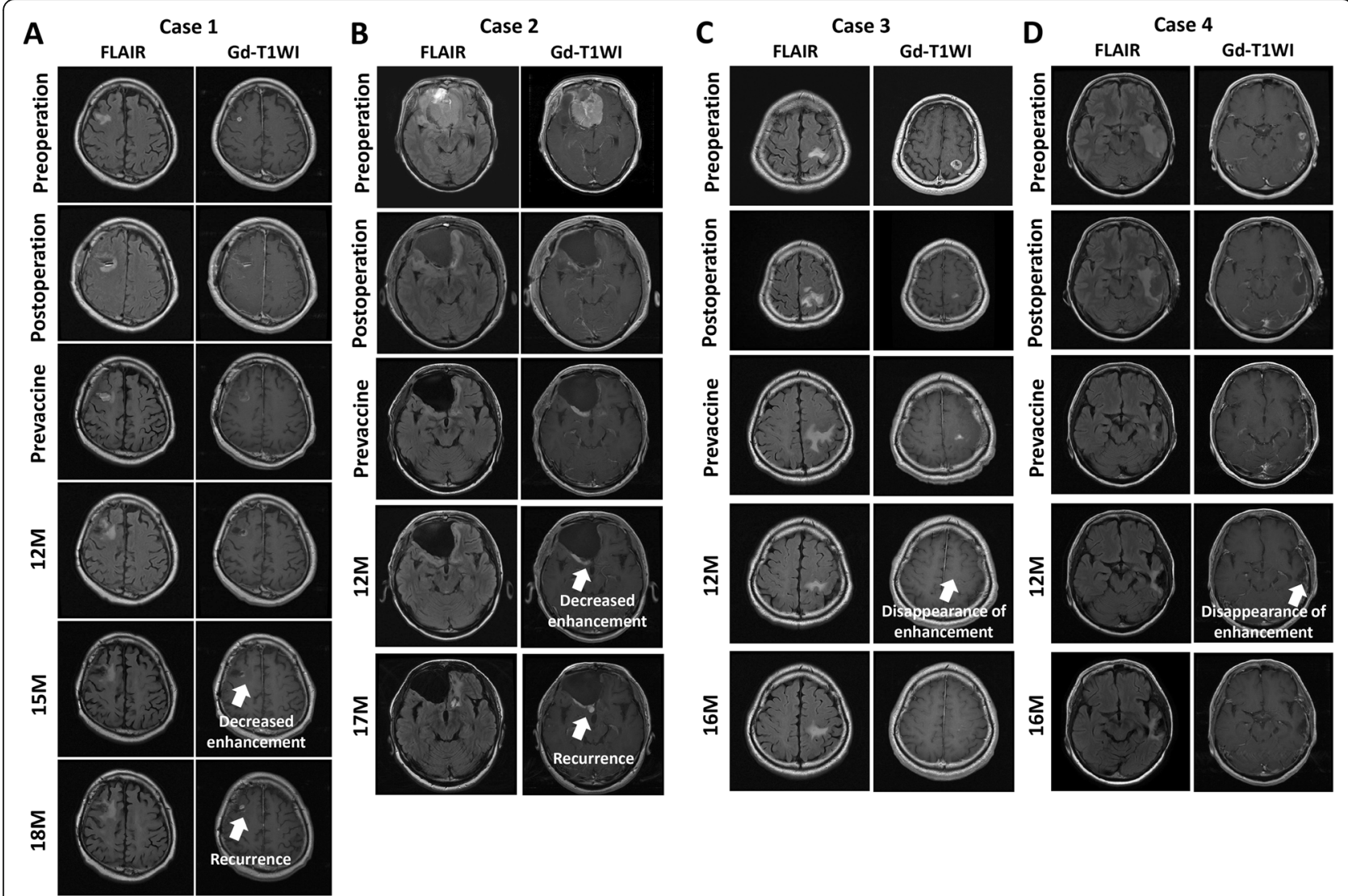

Fig. 2 Radiographic images of enrolled patients. Radiographic images of Case 1(a), Case 2 (b), Case 3 (c), Case 4 (d). a The enhanced lesion was decreased 15 months, and recurrent lesion was observed at the removal site 18 months after the first vaccination. $\mathbf{b}$ The enhanced lesion was decreased 12 months, and recurrent lesion was observed at the removal site 17 months after the first vaccination. $\mathbf{c}$ The enhanced lesion disappeared 12 months after the first vaccination. $\mathbf{d}$ The enhancement lesion disappeared 12 months after the first vaccination

A

Overall Survival

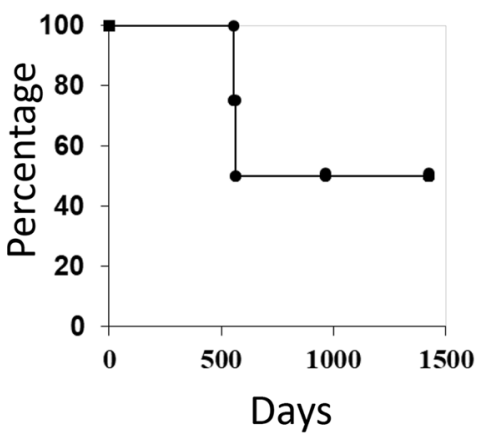

B

\section{Progression-free survival}

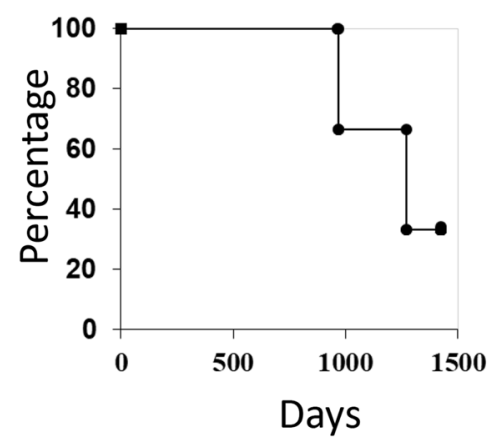

Fig. 3 Clinical course of enrolled patients. a Overall survival of four patients. At the time of analysis, Case 3 and 4 still had CR. $\mathbf{b}$ Progression-free survival of four patients 
Table 3 Clinical results

\begin{tabular}{|c|c|c|c|c|c|c|c|c|c|c|c|}
\hline \multirow{2}{*}{$\begin{array}{l}\text { Case } \\
\text { No. }\end{array}$} & \multirow[t]{2}{*}{ DTH } & \multirow{2}{*}{$\begin{array}{l}\text { Vac } \\
\text { cycles }\end{array}$} & \multirow[t]{2}{*}{ Toxicity } & \multicolumn{3}{|c|}{ ELISPOT (CTL) } & \multicolumn{2}{|c|}{ CTL induction } & \multirow{2}{*}{$\begin{array}{l}\text { PFS } \\
\text { (days) }\end{array}$} & \multirow[t]{2}{*}{ OS (days) } & \multirow{2}{*}{$\begin{array}{l}\text { Evaluation } \\
\text { after } 12 \mathrm{M}\end{array}$} \\
\hline & & & & timing & R1 & R2 & R1 & $\mathrm{R} 2$ & & & \\
\hline \multirow[t]{2}{*}{1} & \multirow[t]{2}{*}{-} & \multirow[t]{2}{*}{14} & \multirow[t]{2}{*}{-} & Before & N/A & N/A & \multirow[t]{2}{*}{ N/A } & \multirow[t]{2}{*}{ N/A } & \multirow[t]{2}{*}{554} & \multirow[t]{2}{*}{967} & \multirow[t]{2}{*}{$P R$} \\
\hline & & & & After & N/A & N/A & & & & & \\
\hline \multirow[t]{2}{*}{2} & \multirow[t]{2}{*}{-} & \multirow[t]{2}{*}{14} & \multirow[t]{2}{*}{-} & Before & N/A & N/A & \multirow[t]{2}{*}{$\mathrm{N} / \mathrm{A}$} & \multirow[t]{2}{*}{ N/A } & \multirow[t]{2}{*}{562} & \multirow[t]{2}{*}{1272} & \multirow[t]{2}{*}{ SD } \\
\hline & & & & After & N/A & N/A & & & & & \\
\hline \multirow[t]{2}{*}{3} & \multirow[t]{2}{*}{ - } & \multirow[t]{2}{*}{14} & \multirow[t]{2}{*}{-} & Before & - & + & \multirow[t]{2}{*}{+} & \multirow[t]{2}{*}{+} & \multirow[t]{2}{*}{-} & \multirow{2}{*}{$\begin{array}{l}\text { Still survive } \\
\text { (1425) }\end{array}$} & \multirow[t]{2}{*}{$C R$} \\
\hline & & & & After & + & $3+$ & & & & & \\
\hline \multirow[t]{2}{*}{4} & \multirow[t]{2}{*}{+} & 14 & - & Before & - & N/A & + & + & - & Still survive (962) & $C R$ \\
\hline & & & & After & $3+$ & $2+$ & & & & & \\
\hline
\end{tabular}

$C T L$ cytotoxic T lymphocyte, DTH delayed type hypersensitivity, $M$ month, $N / A$ not available, $O S$ overall survival, $P D$ progressive disease, $P F S$ progression-free survival, $P R$ partial response, $R$ vascular endothelial growth factor receptor, $S D$ stable disease, Vac vaccination

negative or slight expression of VEGFR1 and 2, and most endothelial cells were covered with PDGFR- $\beta$ positive pericytes (Fig. 4a, b). Tumor cells with VEGFR1 or R2 expression were observed in the pre-vaccination tumor (Fig. 4a). VEGF-A expression after vaccination was also decreased compared with that before vaccination (Fig. 4a). There were fewer Foxp3-positive cells in the post-vaccination tumor compared with that of prevaccination (Fig. 4e). qPCR analysis revealed that the mean relative expressions of VEGF-A, VEGFRs, and Foxp3 genes in the post-vaccination tumors were lower than that of the pre-vaccination tumor (Fig. 4g). More number of cleaved caspase 3 positive cells were detected in post-vaccination tumor than in pre-vaccination tumor. In the post-vaccination tumor, the expression of cleaved caspase 3 was co-localized in endothelial cells with CD34-positive staining and Foxp3-positive cells (Fig. 4c, d, e, f). In contrast, the number of CD163, CD8, and CD4-positive cells did not change after vaccination. Immune checkpoint molecules, such as PD-1/PD-L1 and, a marker of glioma stem cell-like phenotype, such as nestin did not change either after vaccination (Additional file 1: Figure S1 A,B,C).

\section{Discussion}

VEGF /VEGFRs signaling plays a pivotal role in the tumor angiogenesis and the development of the immunosuppressive tumor microenvironment in glioblastomas by inhibiting the maturation of dendritic cells (DCs) and stimulating the proliferation of Tregs, TAMs, and myeloid-derived suppressor cells (MDSCs) with VEGFRs expressions [7, 29-32]. Therefore, anti-angiogenic therapy targeting VEGF and/or VEGFRs, including VEGFRs peptide vaccination, has not only anti-angiogenic effects, but also immune-supportive effects $[19,26]$. In addition, VEGFRs peptide vaccination has the advantages of immunotherapy. CTLs induced by the vaccination may persist in the long-term. In the present study, the synergistic activity of the combinational usage of VEGFRs peptide vaccination and TMZ-based chemotherapy was investigated for the patients with primary glioblastomas.

In this study, the disappearance of a radiographically enhanced lesion in the patient with unmethylated MGMT promoter was suggestive. The histopathological changes after the VEGFRs vaccination using paired preand post-vaccination specimens demonstrated that VEGFR1 and 2 peptide vaccination induced the normalization of vascular structure with decreased VEGFR1 and 2 expressions, and the reduction of MVD in the recurrent tumor after vaccination. We have previously reported the histopathological changes after the administration of bevacizumab (anti-VEGF-A monoclonal antibody) using actual human glioblastoma specimens resected in 3 different settings: glioblastomas before any treatment; glioblastomas resected following bevacizumab therapy; and recurrent glioblastomas after long-term bevacizumab therapy [26, 27, 33]. In these previous studies, the expressions of VEGFR1 and 2 were upregulated in recurrent glioblastomas after longterm bevacizumab therapy [33]. The present histopathological results might suggest that memory CTL induced by VEGFRs peptide vaccination may overcome the problems of anti-angiogenic molecular targeting agents, which include apparent drug resistance and rebound upregulated VEGF-A/VEGFRs signaling [34]. However, peptide-based vaccination results in the induction of $\mathrm{T}$ cell exhaustion. The transient upregulation of PD-1 during T-cell activation and its maintenance on chronically stimulated exhausted $\mathrm{T}$ cells enable PD-1 to negatively regulate $\mathrm{T}$-cell function $[35,36]$. Therefore, Immune checkpoint inhibition may exert synergic effects when administered with this type of CTL-mediated antitumor immunotherapy. In the future, we will reveal the difference in the target of inhibition, VEGF compared with VEGFRs using these valuable human tumor specimens. 


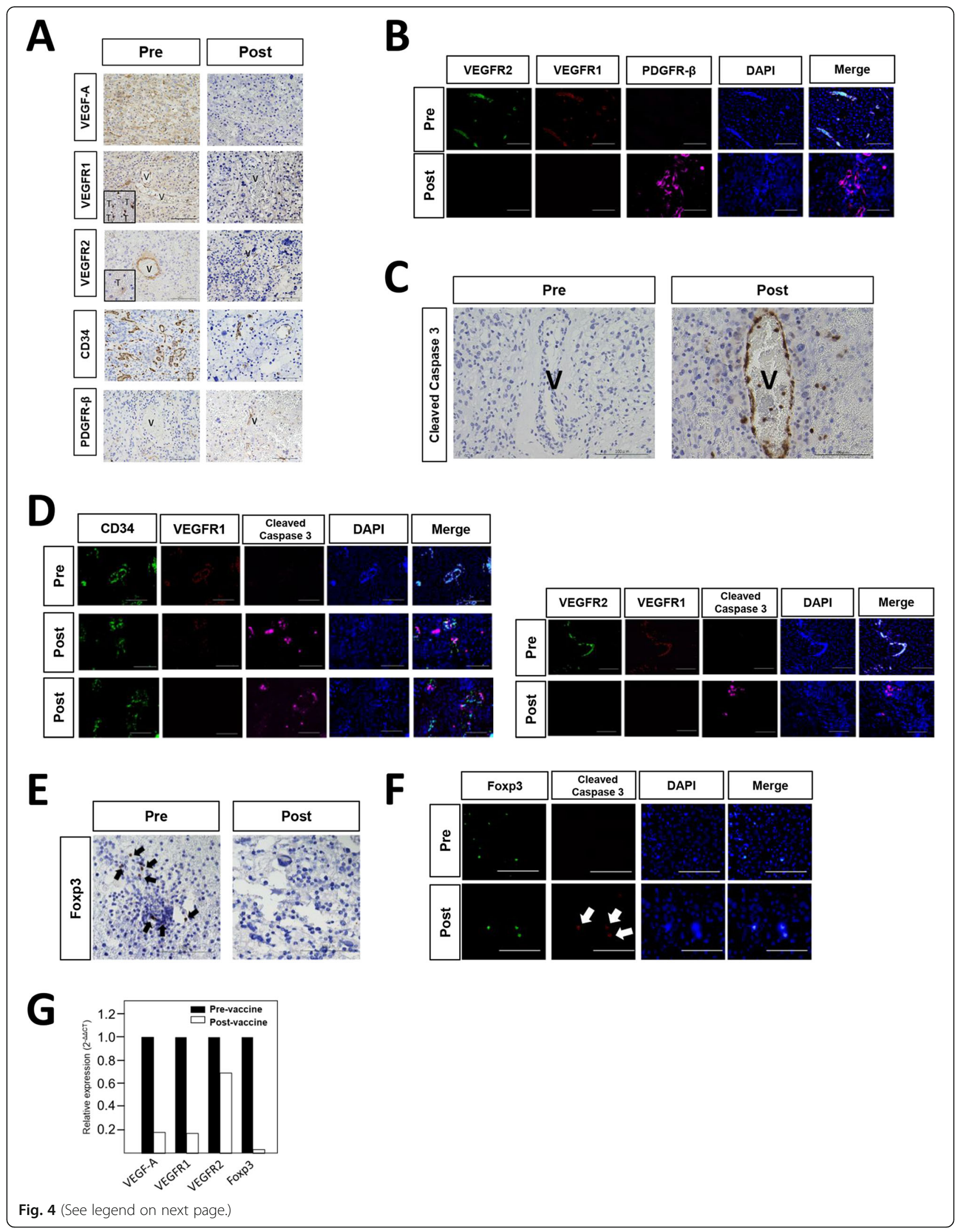


(See figure on previous page.)

Fig. 4 Histopathological images of the paired pre- and post-vaccination. a Histopathological analysis of VEGF-A, VEGFR1, VEGFR2, CD34 and PDGFR- $\beta$ expressions in the tumor of pre- and post- vaccination. A square means tumor cells with positive VEGFR1 or VEGFR2 staining (T: tumor cell, V: vessel; original magnification, $\times 40$; magnification bar, $100 \mu \mathrm{m})$. b Immunofluorescent analysis of VEGFR1, VEGFR2 and PDGFR- $\beta$ expressions in tumor vessels in pre- and post- vaccination (original magnification, $\times 40$; magnification bar, $100 \mu \mathrm{m}$ ). c Histopathological analysis of cleaved caspase 3 expression on the tumor vessel of pre- and post- vaccination. (V: vessel; original magnification, $\times 40$; magnification bar, $100 \mu \mathrm{m}) . \mathbf{d}$ Immunofluorescent analysis of CD34, VEGFR1, and cleaved caspase3 expressions in the tumor of pre- and post- vaccination. Expression of cleaved caspase 3 was detected on the endothelial cells with slight VEGFR1 expression or without VEGFR1 expression (original magnification, $\times 40$; magnification bar, $100 \mu \mathrm{m}$ ). e Histopathological analysis of Foxp3 expression in the tumor of pre- and post- vaccination (original magnification, $x$ 40; magnification bar, 100 um; black arrows, positive cells). $\mathbf{f}$ Immunofluorescent analysis of Foxp3 and cleaved caspase3 expressions in the tumor of pre- and post- vaccination (original magnification, $\times 40$; magnification bar, $100 \mu \mathrm{m}$; white arrow, positive cells). $\mathbf{g}$ Relative gene expression of VEGF-A, VEGFR1, VEGFR2 and Foxp3 in the tumors of pre- and post- vaccination

Furthermore, the combinational usage of chemotherapy and immunotherapy was reported to be effective with synergistic activity [19-21]. The combination of TMZ and immunotherapy with fusions of dendritic cells (DCs) and glioma cells safely induced anti-tumor effects in patients with glioblastomas [37]. However, the Tregs population increases rapidly, known as the rebound phenomenon, during long-term TMZ therapy for glioblastomas [38]. Importantly, the present histopathological finding of cleaved caspase 3 also proved that VEGFR1 and 2 peptide vaccination could target wide variety of cells associated with tumor growth, such as vascular endothelial cells, tumor cells, and Foxp3 + Tregs expressing VEGFR1 and/or VEGFR2, which was considered as one of the rationales behind using VEGFRs peptide vaccination with TMZ. Previous study also demonstrated that VEGFR2-targeting treatment has the possibility of selectively killing Tregs, because Foxp3(+) Tregs express VEGFR2 [39, 40], which was compatible with the present results.

Although immunotherapy has become an increasingly available and vital cancer treatment option, it has some disadvantages. Immunotherapy's potential side effects result from an overstimulated or misdirected immune response. However, fewer severe side effects were reported in the clinical setting. The clinical trials with peptidebased vaccine therapy using VEGFR-derived epitopes have been previously conducted for the patients with advanced gastrointestinal cancers and renal cell cancer, wherein the treatment exhibited the safety (Additional file 2: Table S1) [20, 41-47]. Chemotherapy attacks all rapidly-dividing cells within the body, effectively targeting fast-growing tumors. In contrast, immunotherapy takes longer time to work compared with other treatments [48].

The present study might demonstrate that the preliminary safety and immunogenicity of this approach. VEGFR1 and 2-specific CTLs inductions were detected under treatment with TMZ. In addition, paired pre- and post-vaccination specimens suggested that VEGFR1 and 2 peptide vaccination may possibly enhance the effects of TMZ. The limitation of the present study was the paucity of the number of enrolled patients. Further studies involving more patients are warranted to confirm the findings of this study.

\section{Conclusions}

This is the first clinical trial of combinational therapy with VEGFRs peptide-based vaccines plus TMZ in patients with primary glioblastomas. Paired pre- and postvaccination specimens suggested that VEGFRs peptide vaccination may possibly enhance the effects of TMZ. Further studies involving more patients are warranted to confirm the findings of this study.

\section{Supplementary information}

Supplementary information accompanies this paper at https://doi.org/10. 1186/s12885-020-6589-x.

Additional file 1: Figure S1. Other factors in the tumor

microenvironment. The expression of PD-1 and PD-L1 (A), nestin (B), and CD 163, CD8, CD4 (C) in the tumors of pre- and post- vaccination. The number of positive cells did not change after vaccination. (original magnification, $\times$ 40; magnification bar, $100 \mu \mathrm{m}$; black arrows, positive cells).

Additional file 2: Table S1. Review of reported clinical trials using VEGFR1 or 2 peptide vaccine.

Additional file 3. Appendix.

\section{Abbreviations}

BCNU: 1,3-bis-Chloroethyl-1-Nitrosourea; CAN: Chromosomal number aberrations; CR: Complete response; CT: Computed tomography; CTL: Cytotoxic T Iymphocytes; DC: Dendritic cell; ELISPOT: Enzyme-linked immunoSpot; FLAIR: Fluid attenuated IR; Gd: Gadolinium; GMP: Good manufacturing practice; HPLC: High-performance liquid chromatography; IDH: Isocitrate dehydrogenase; MDSC: Myeloid-derived suppressor cells; MGMT: O6-methylguanine DNA methyltransferase; MRI: Magnetic resonance imaging; MVD: Microvessel density; OS: Overall survival; PDGFR: Plateletderived growth factor receptor; qPCR: Quantitative real-time PCR; RT: Radiotherapy; TAM: Tumor-associated macrophage; TMZ: Temozolomide; VEGF: Vascular endothelial growth factor; VEGFR: Vascular endothelial growth factor receptor

\section{Acknowledgments}

The authors greatly thank Ms. Naoko Tsuzaki in the department of Neurosurgery for technical assistance of laboratory works, and the enago group (www.enago.jp/) for editing a draft of this manuscript. 


\section{Authors' contributions}

MT is the principal investigator of this study. RT, YM, KK, YO, MS, RK, and HN were study investigators. RT, YM and MT did the statistical analysis. RT, YM, RU, YK, HS, KY and MT designed the clinical trial. RT, YM, KK, YO, MS, RK, HN and SN collected the data. RT, YM, KK, YO, MS, SN, HS, YK, KY, and MT analyzed and interpreted data. All authors contributed to the writing of the report and approved the final version.

\section{Funding}

This work was supported in part by grants from the Japan Society for the Promotion of Science (JSPS) (17H04306 and 18K19622 to M.T., and 18 J21382 to R.T.). The role of the funder was data collection and analysis.

\section{Availability of data and materials}

All data supporting the findings of this study are available within the article and its Supplementary Information Files and from the corresponding author on reasonable request.

\section{Ethics approval and consent to participate}

Written informed consent was obtained from all individual participants included in the study. The authors affirm that all individual participants provided informed consent for publication of their data. All procedures performed in studies involving human participants were in accordance with the ethical standards of the Keio University School of Medicine Ethics Committee (reference number: 20130461) and with the 1964 Helsinki declaration and its later amendments or comparable ethical standards.

\section{Consent for publication}

All clinical details of participants were anonymized.

\section{Competing interests}

$\mathrm{TH}$ is an employee of OncoTherapy Science, Inc

\section{Author details}

'Department of Neurosurgery, Keio University School of Medicine, 35 Shinanomachi, Shinjuku-ku, Tokyo 160-8582, Japan. ${ }^{2}$ Department of Neurosurgery, Hiratsuka City Hospital, Hiratsuka, Kanagawa 254-0019, Japan. ${ }^{3}$ Division of Cellular Signaling Institute for Advanced Medical Research, Keio University School of Medicine, 35 Shinanomachi, Shinjuku-ku, Tokyo 160-8582, Japan. ${ }^{4}$ OncoTherapy Science, Inc., 3-2-1, Sakado, Takatsu-ku, Kawasaki City, Kanagawa 213-0012, Japan.

\section{Received: 10 September 2019 Accepted: 29 January 2020}

\section{Published online: 12 March 2020}

\section{References}

1. Jain RK, di Tomaso E, Duda DG, Loeffler JS, Sorensen AG, Batchelor TT. Angiogenesis in brain tumours. Nat Rev Neurosci. 2007;8:610-22.

2. Chaudhry IH, O'Donovan DG, Brenchley PE, Reid H, Roberts IS. Vascular endothelial growth factor expression correlates with tumour grade and vascularity in gliomas. Histopathology. 2001;39:409-15.

3. Tamura R, Ohara K, Sasaki H, Morimoto Y, Yoshida K, Toda M. Histopathological vascular investigation of the peritumoral brain zone of glioblastomas. J Neuro-Oncol. 2018;136:233-41.

4. Goel HL, Mercurio AM. VEGF targets the tumour cell. Nat Rev Cancer. 2013: 13:871-82.

5. Roskoski R. Vascular endothelial growth factor (VEGF) signaling in tumor progression. Crit Rev Oncol Hematol. 2007:62:179-213.

6. Hamerlik P, Lathia JD, Rasmussen R, Wu Q, Bartkova J, Lee M, Moudry P, Bartek J Jr, Fischer W, Lukas J, Rich JN, Bartek J. Autocrine VEGF-VEGFR2Neuropilin-1 signaling promotes glioma stem-like cell viability and tumor growth. J Exp Med. 2012;209:507-20.

7. Tamura R, Tanaka T, Akasaki Y, Murayama Y, Yoshida K, Sasaki H. The role of vascular endothelial growth factor in the hypoxic and immunosuppressive tumor microenvironment: perspectives for therapeutic implications. Med Oncol. 2019;37:2.

8. Batchelor TT, Duda DG, di Tomaso E, Ancukiewicz M, Plotkin SR, Gerstner E, Eichler AF, Drappatz J, Hochberg FH, Benner T, Louis DN, Cohen KS, Chea H, Exarhopoulos A, Loeffler JS, Moses MA, Ivy P, Sorensen AG, Wen PY, Jain RK. Phase II study of cediranib, an oral pan-vascular endothelial growth factor receptor tyrosine kinase inhibitor, in patients with recurrent glioblastoma. J Clin Oncol. 2010;28:2817-23.

9. Chinot OL, Wick W, Mason W, Henriksson R, Saran F, Nishikawa R, Carpentier AF, Hoang-Xuan K, Kavan P, Cernea D, Brandes AA, Hilton M, Abrey L, Cloughesy T. Bevacizumab plus radiotherapy-temozolomide for newly diagnosed glioblastoma. N Engl J Med. 2014;370:709-22.

10. Gilbert MR, Dignam JJ, Armstrong TS, Wefel JS, Blumenthal DT, Vogelbaum MA, Colman H, Chakravarti A, Pugh S, Won M, Jeraj R, Brown PD, Jaeckle KA, Schiff D, Stieber WW, Brachman DG, Werner-Wasik M, Tremont-Lukats IW, Sulman EP, Aldape KD, Curran WJ Jr, Mehta MP. A randomized trial of Bevacizumab for newly diagnosed Glioblastoma. N Engl J Med. 2014;370: 699-708.

11. Hainsworth JD, Ervin T, Friedman E, Priego V, Murphy PB, Clark BL, Lamar RE. Concurrent radiotherapy and temozolomide followed by temozolomide and sorafenib in the first-line treatment of patients with glioblastoma multiforme. Cancer. 2010;116:3663-9.

12. Koutras AK, Krikelis D, Alexandrou N, Starakis I, Kalofonos HP. Brain metastasis in renal cell cancer responding to sunitinib. Anticancer Res. 2007; 27:4255-7.

13. Ma J, Waxman DJ. Combination of antiangiogenesis with chemotherapy for more effective cancer treatment. Mol Cancer Ther. 2008;7:3670-84.

14. Stupp R, Mason WP, van den Bent MJ, Weller M, Fisher B, Taphoorn MJ, Belanger K, Brandes AA, Marosi C, Bogdahn U, Curschmann J, Janzer RC, Ludwin SK, Gorlia T, Allgeier A, Lacombe D, Cairncross JG, Eisenhauer E, Mirimanoff RO. Radiotherapy plus concomitant and adjuvant temozolomide for glioblastoma. N Engl J Med. 2005;352:987-96.

15. Zustovich F, Landi L, Lombardi G, Porta C, Galli L, Fontana A, Amoroso D, Galli C, Andreuccetti M, Falcone A, Zagonel V. Sorafenib plus daily low-dose temozolomide for relapsed glioblastoma: a phase II study. Anticancer Res. 2013;33:3487-94.

16. Shibao S, Ueda R, Saito K, Kikuchi R, Nagashima H, Kojima A, Kagami H, Pareira ES, Sasaki H, Noji S, Kawakami Y, Yoshida K, Toda M. A pilot study of peptide vaccines for VEGF receptor 1 and 2 in patients with recurrent/ progressive high grade glioma. Oncotarget. 2018;9:21569-79.

17. Kikuchi R, Ueda R, Saito K, Shibao S, Nagashima H, Tamura R, Morimoto Y, Sasaki H, Noji S, Kawakami Y, Yoshida K, Toda M. A pilot study of vaccine therapy with multiple Glioma Oncoantigen/Glioma angiogenesis-associated antigen peptides for patients with recurrent/progressive high-grade Glioma. J Clin Med. 2019;8:E263.

18. Tamura R, Fujioka M, Morimoto Y, Ohara K, Kosugi K, Oishi Y, Sato M, Ueda R, Fujiwara H, Noji S, Oishi N, Ogawa K, Kawakami Y, Ohira T, Yoshida K, Toda M. A VEGF receptor vaccine demonstrates preliminary efficacy in neurofibromatosis type 2. Nat Commun. 2019;10:5758.

19. Ramakrishnan R, Gabrilovich DI. Mechanism of synergistic effect of chemotherapy and immunotherapy of cancer. Cancer Immunol Immunother. 2011;60:419-23.

20. Miyazawa M, Ohsawa R, Tsunoda T, Hirono S, Kawai M, Tani M, Nakamura Y, Yamaue H. Phase I clinical trial using peptide vaccine for human vascular endothelial growth factor receptor 2 in combination with gemcitabine for patients with advanced pancreatic cancer. Cancer Sci. 2010;101:433-9.

21. Ramakrishnan R, Assudani D, Nagaraj S, Hunter T, Cho HI, Antonia S, Altiok S, Celis E, Gabrilovich DI. Chemotherapy enhances tumor cell susceptibility to CTL-mediated killing during cancer immunotherapy in mice. J Clin Invest. 2010;120:1111-24.

22. Okada H, Weller M, Huang R, Finocchiaro G, Gilbert MR, Wick W, Ellingson BM, Hashimoto N, Pollack IF, Brandes AA, Franceschi E, Herold-Mende C, Nayak L, Panigrahy A, Pope WB, Prins R, Sampson JH, Wen PY, Reardon DA. Immunotherapy response assessment in neurooncology: a report of the RANO working group. Lancet Oncol. 2015;16:e534-42.

23. Wen PY, Macdonald DR, Reardon DA, Cloughesy TF, Sorensen AG, Galanis E, Degroot J, Wick W, Gilbert MR, Lassman AB, Tsien C, Mikkelsen T, Wong ET, Chamberlain MC, Stupp R, Lamborn KR, Vogelbaum MA, van den Bent MJ, Chang SM. Updated response assessment criteria for high-grade gliomas: response assessment in neuro-oncology working group. J Clin Oncol. 2010; 28:1963-72.

24. Ranieri E, Popescu I, Gigante M. CTL ELISPOT assay. Methods Mol Biol. 2014; 1186:75-86.

25. Hirose Y, Aldape K, Takahashi M, Berger MS, Feuerstein BG. Tissue microdissection and degenerate oligonucleotide primed-polymerase chain reaction (DOP-PCR) is an effective method to analyze genetic aberrations in invasive tumors. J Mol Diagn. 2001;3:62-7. 
26. Tamura R, Tanaka T, Ohara K, Miyake K, Morimoto Y, Yamamoto Y, Kanai R, Akasaki Y, Murayama Y, Tamiya T, Yoshida K, Sasaki H. Persistent restoration to the immunosupportive tumor microenvironment in glioblastoma by bevacizumab. Cancer Sci. 2018;110:499-508.

27. Tamura R, Tanaka T, Miyake K, Tabei Y, Ohara K, Sampetrean O, Kono M, Mizutani K, Yamamoto Y, Murayama Y, Tamiya T, Yoshida K, Sasaki H. Histopathological investigation of glioblastomas resected under bevacizumab treatment. Oncotarget. 2016;7:52423-35.

28. Tamura R, Ohara K, Morimoto Y, Kosugi K, Oishi Y, Sato M, Yoshida K, Toda M. PITX2 expression in non-functional pituitary neuroendocrine tumor with cavernous sinus invasion. Endocr Pathol. 2019;30:81-9.

29. Gabrilovich DI, Chen HL, Girgis KR, Cunningham HT, Meny GM, Nadaf S, Kavanaugh D, Carbone DP. Production of vascular endothelial growth factor by human tumors inhibits the functional maturation of dendritic cells. Nat Med. 1996:2:1096-103.

30. Ohm JE, Gabrilovich DI, Sempowski GD, Kisseleva E, Parman KS, Nadaf S, Carbone DP. VEGF inhibits T-cell development and may contribute to tumor-induced immune suppression. Blood. 2003;101:4878-86.

31. Li YL, Zhao H, Ren XB. Relationship of VEGFNEGFR with immune and cancer cells: staggering or forward? Cancer Biol Med. 2016;13:206-14.

32. Yang J, Yan J, Liu B. Targeting VEGFNEGFR to modulate antitumor immunity. Front Immunol. 2018;9:978.

33. Yamamoto $Y$, Tamura R, Tanaka T, Ohara K, Tokuda Y, Miyake K, Takei J, Akasaki Y, Yoshida K, Murayama Y, Sasaki H. "paradoxical" findings of tumor vascularity and oxygenation in recurrent glioblastomas refractory to bevacizumab. Oncotarget. 2017;8:103890-9.

34. Tamura R, Tanaka T, Miyake K, Yoshida K, Sasaki H. Bevacizumab for malignant gliomas: current indications, mechanisms of action and resistance, and markers of response. Brain Tumor Pathol. 2017;34:62-77.

35. Iwai Y, Terawaki S, Ikegawa M, Okazaki T, Honjo T. PD-1 inhibits antiviral immunity at the effector phase in the liver. J Exp Med. 2003;198:39-50.

36. Pauken KE, Wherry EJ. Overcoming $T$ cell exhaustion in infection and cancer. Trends Immunol. 2015;36:265-76.

37. Akasaki Y, Kikuchi T, Homma S, Koido S, Ohkusa T, Tasaki T, Hayashi K, Komita H, Watanabe N, Suzuki Y, Yamamoto Y, Mori R, Arai T, Tanaka T, Joki T, Yanagisawa T, Murayama Y. Phase I/II trial of combination of temozolomide chemotherapy and immunotherapy with fusions of dendritic and glioma cells in patients with glioblastoma. Cancer Immunol Immunother. 2016;65:1499-509.

38. Batich KA, Reap EA, Archer GE, Sanchez-Perez L, Nair SK, Schmittling RJ, Norberg P, Xie W, Herndon JE 2nd, Healy P, McLendon RE, Friedman AH, Friedman HS, Bigner D, Vlahovic G, Mitchell DA, Sampson JH. Long-term Survival in Glioblastoma with Cytomegalovirus pp65-Targeted Vaccination. Clin Cancer Res. 2017:23:1898-909.

39. Suzuki H, Onishi H, Wada J, Yamasaki A, Tanaka H, Nakano K, Morisaki T, Katano M. VEGFR2 is selectively expressed by FOXP3high CD4+ Treg. Eur J Immunol. 2010:40:197-203.

40. Terme M, Pernot S, Marcheteau E, Sandoval F, Benhamouda N, Colussi O, Dubreuil O, Carpentier AF, Tartour E, Taieb J. VEGFA-VEGFR pathway blockade inhibits tumor-induced regulatory T-cell proliferation in colorectal cancer. Cancer Res. 2013;73:539-49.

41. Hazama S, Nakamura Y, Takenouchi H, Suzuki N, Tsunedomi R, Inoue $Y$, Tokuhisa Y, lizuka N, Yoshino S, Takeda K, Shinozaki H, Kamiya A, Furukawa H, Oka M. A phase I study of combination vaccine treatment of five therapeutic epitope-peptides for metastatic colorectal cancer; safety, immunological response, and clinical outcome. J Transl Med. 2014;12:63.

42. Hazama S, Nakamura Y, Tanaka H, Hirakawa K, Tahara K, Shimizu R, Ozasa H, Etoh R, Sugiura F, Okuno K, Furuya T, Nishimura T, Sakata K, Yoshimitsu K, Takenouchi H, Tsunedomi R, Inoue Y, Kanekiyo S, Shindo Y, Suzuki N, Yoshino S, Shinozaki H, Kamiya A, Furukawa H, Yamanaka T, Fujita T, Kawakami Y, Oka M. A phase II study of five peptides combination with oxaliplatin-based chemotherapy as a first-line therapy for advanced colorectal cancer (FXV study). J Transl Med. 2014;12:108.

43. linuma H, Fukushima R, Inaba T, Tamura J, Inoue T, Ogawa E, Horikawa M, Ikeda Y, Matsutani N, Takeda K, Yoshida K, Tsunoda T, Ikeda T, Nakamura Y, Okinaga K. Phase I clinical study of multiple epitope peptide vaccine combined with chemoradiation therapy in esophageal cancer patients. $J$ Transl Med. 2014;12:84.

44. Ishizaki H, Tsunoda T, Wada S, Yamauchi M, Shibuya M, Tahara H. Inhibition of tumor growth with antiangiogenic cancer vaccine using epitope peptides derived from human vascular endothelial growth factor receptor 1 Clin Cancer Res. 2006;12:5841-9.

45. Masuzawa T, Fujiwara Y, Okada K, Nakamura A, Takiguchi S, Nakajima K, Miyata H, Yamasaki M, Kurokawa Y, Osawa R, Takeda K, Yoshida K, Tsunoda T, Nakamura Y, Mori M, Doki Y. Phase I/II study of S-1 plus cisplatin combined with peptide vaccines for human vascular endothelial growth factor receptor 1 and 2 in patients with advanced gastric cancer. Int J Oncol. 2012;41:1297-304.

46. Wada S, Tsunoda T, Baba T, Primus FJ, Kuwano H, Shibuya M, Tahara H. Rationale for antiangiogenic cancer therapy with vaccination using epitope peptides derived from human vascular endothelial growth factor receptor 2 Cancer Res. 2005;65:4939-46.

47. Yoshimura K, Minami T, Nozawa M, Uemura H. Phase I clinical trial of human vascular endothelial growth factor receptor 1 peptide vaccines for patients with metastatic renal cell carcinoma. Br J Cancer. 2013;108:1260-6.

48. Yu Y, Cui J. Present and future of cancer immunotherapy: a tumor microenvironmental perspective. Oncol Lett. 2018;16:4105-13.

\section{Publisher's Note}

Springer Nature remains neutral with regard to jurisdictional claims in published maps and institutional affiliations.

Ready to submit your research? Choose BMC and benefit from:

- fast, convenient online submission

- thorough peer review by experienced researchers in your field

- rapid publication on acceptance

- support for research data, including large and complex data types

- gold Open Access which fosters wider collaboration and increased citations

- maximum visibility for your research: over $100 \mathrm{M}$ website views per year

At $\mathrm{BMC}$, research is always in progress.

Learn more biomedcentral.com/submissions 